entirely separate it. When iron in solution is brought into contact with the body termed tannic acid, the two combine and form a black substance, which is the basis of most kinds of black ink. Tannic acid is a natural ingredient of tea; if, therefore, sugar containing iron be dissolved in an infusion of tea, the fluid will instantly acquire an inky hue. The presence of a small quantity of iron in sugar does not in the slightest degree injure its nutritive or healthful qualities; still as tea resembling ink in appearance, however agreeable to the palate, would be displeasing to the eye, sugar which would thus affect its color is unfitted for domestic use.

"Would any one, with the slightest pretension to cleanly notions, drink stagnant water if he coald as easily obtain the element pure and sparkling from the fountain? May I not add, is there any one so indifferent as to the purity of his food, who would consume raw sugar, knowing it to be teeming with disgusting forms of animal life, if the pure article were as readily obtainable? The sanitary reformers have clearly proved that the health of a community is, to a great extent, dependent upon the quality of the water they drink; and the public at large accept the results of the philosopher's reasoning. At the present moment the citizens of Dublin are heavily increasing their already ponderous load of taxation for the purpose of obtaining an abundant supply of pure water. The water which the citizens of Dublin at present use is considered unwholesome, because it contains low forms of vegetable life, and abounds in animalcules; and these are just the kinds of impurities which exist-but in immensely greater quantities-in raw sugar. Is it not, therefore, but rational that if we substititute the pellucid water of the Vartry for the stagnant fluid of the canals, we should for the same reason reject the filthy raw sugar, and supply its place with the purified products of the refiner? The parallelism, in a sanitary point of view, between bad water and raw sugar is complete: it is equally so between pure water and refined sugar."

\title{
ON THE INFLAMMABILITY OF PETROLEUM AND SCHIST OILS,
}

\section{By Dr. Robert Peltzer.}

(Translated from Dingler's Polytechnic Journal, Vol. 189, page 61, by Dr. Adolph Ott.)

I HAVE lately made experiments on the inflammability of different products of distillation which were derived from Pennsylvania petroleum and bituminous schists from Autun, Dept. Saône and 
Loire in France. The same were conducted in the refinery of Messrs. Cogniet, Maréchal \& $\mathrm{C}$., and made by the special request: of M. Cogniet. The following are the results of these experiments :

\begin{tabular}{|c|c|c|c|}
\hline \multicolumn{2}{|c|}{ PETROLEUM. } & \multicolumn{2}{|c|}{ SCBIST OIL. } \\
\hline Density. & $\begin{array}{l}\text { Inflammability } \\
\text { Takes fire at- }\end{array}$ & Density. & $\begin{array}{l}\text { Inflammability. } \\
\text { Takes fire at- }\end{array}$ \\
\hline $\begin{array}{c}0.643 \\
0.686 \\
0.700 \\
0.740 \\
0.748 \\
0.750 \\
0.760 \\
0.775 \\
0.783 \\
0.792 \\
0.895 \\
0.822 \\
0.831 \\
0.848 \\
0.550 \\
0.802 \\
\text { Crude petroleum of } \\
0.802 \\
\text { Heavy oils from the } \\
\text { distillation of kero- } \\
\text { Eene. } \\
\text { Paraifine of melting } \\
\text { point } 129.2^{\circ} \mathrm{F} \text {. }\end{array}$ & 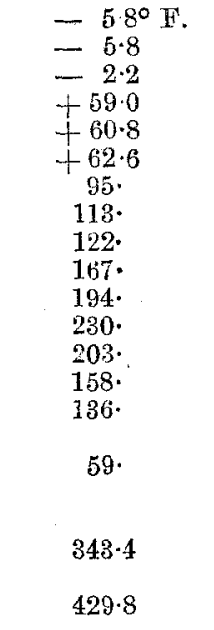 & 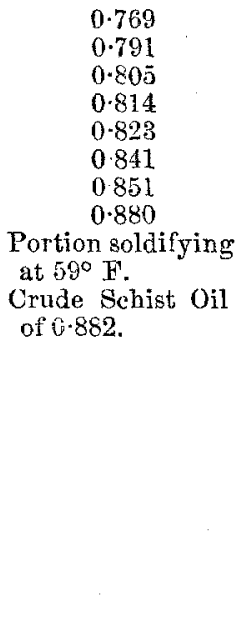 & $\begin{array}{c}+10 \cdot 4^{\circ} \mathrm{F} \\
66 \cdot 2 \\
95 \cdot \\
118 \cdot 4 \\
140 \cdot \\
176 \cdot \\
186 \cdot 8 \\
208 \cdot 4 \\
206 \cdot 6 \\
82 \cdot 4\end{array}$ \\
\hline
\end{tabular}

The oils were heated in a small capsule over a water or paraffine bath, a thermometer being inserted in the oil, and a thin burning wick being held over the same.

The petroleum oils which were experimented upon, were very differently obtained, a part of them were gathered directly from the cooling worms in refineries, others were obtained by fractional distillation in small retorts, and still others by evaporation of specifically light mixtures.

The two first samples of the density of 0.643 and 0.686 already took fire at $5.8^{\circ} \mathrm{I}$., henceforth the inflammability diminishes till the density of 0.822 is reached. From this point we again see it increase. This remarkable fact is easily explained, when we consider that the high temperature which is necessary to distil the oils of 0.822 , is sufficient to produce a partial decomposition of the higher boiling oils in the retort. 
This admission is sufficiently confirmed by the experiment. When the distilled oils had reached the density of 0.822 , the fan under the retort was drawn out. In producing a light oil of 0.800 , distillers generally gather only the portions which come up to this point; the first fractions which are used with the illuminating oil possess a specific weight of 0.750 ; the mixture does not then take fire below $96.7^{\circ} \mathrm{F}$. The remainder in the retort may be heated to $343^{\circ} \mathrm{F}$. before it is inflamed by a burning wick. When, however, after the distillate had reached the specific gravity of 0.822 , the heat was increased, as it is done for the production of lubricating oils; the inflammability was also increased, as is seen from the foregoing table.

Refined paraffine of a melting point of $129 \cdot 2^{\circ} \mathrm{F}$., could be heated to $429.8^{\circ} \mathrm{F}$; it then took fire, but without a prior decomposition being noticed, which obviously had taken place in the distillation of the heavy oils and crude oil containing paraffine masses.

The schist oil samples were obtained from a distillation on a small scale. The same was carried out in a cast iron retort of $2 \frac{1}{2}$ gallons capacity on naked fire. The oils were purified and from Autun. It is striking that the latter are a great deal more inflammable than the petroleum oils of the same density. Prof. Maroc, of Stuttgardt, also indicates the inflammability of a schist oil, which he does not designate further than as being at $63.5^{\circ} \mathrm{F}$.

It is highly probable that a similar decomposition goes on in the distillation of schist oils at an elevated temperature, only in a less striking manner than is the case with petroleum. Unhappily, my choice was very limited, and I was specially in want of the distillates from the crude heavy oils for the production of Iubricators, otherwise the decomposition of the schist oils could have been more precisely determined.

Upon this decomposition a process coutd be founded for changing the heavy petroleum oils by a high heat (at least partially) into illuminating oils, as Mr. Breitenlohner, of Chlumetz, Bohemia, has already done with heavy peat oils.*

This principle has already found application in the refinery of Messrs. Cogniet, Maréchal \& Co., as yet, however, on a very limited scale.

From the foregoing table we notice a diminution of the inflammability with the increase of density in case no decomposition has

* Polytechnic Journal of Dingler, CLXVII., page 378. 
yet taken place by too elevated a temperature; but even an approximate relation between these two points is, however, not perceivable. If the greater or less inclination of the oils to inflame, was simply dependent upon the boiling points of the single fractions, which would represent more or less constant mixtures of hydro-carbons of the series $\mathrm{C}^{2_{n}} \mathrm{H}^{2 \mathrm{n}} \times 2$, as isolated by Cahours, Pelouze* and Schorlemmert than a fixed relation between the inflammability and density would be the necessary consequence; this relation is, however, very probably concealed by a different degree of absopption by the various "fractions" of the highly inflammable gases, which are met with in the oils.

A fraction which holds a certain quantity of gas, possesses also a corresponding inclination to inflame.

For making the crude petroleum applicable and perfectly safe for the heating of steam boilers, it would be necessary to separate all the oils until the density of 0.783 is reached, and then to free it from the absorbed gases. Though oils may yet be present, which are inflammable from $1 \cdot 22$ to $1.67^{\circ} \mathrm{F}$, their per centage is so small that the fluid will bear a heat of $176^{\circ}$ to $212^{\circ} \mathrm{F}$. without there being any danger of explosion. The oil below the density of 0.783 could be sold partly as kerosene, partly as essence for the so-called magic lamp.

\section{LECTURE-NOTES ON PHYSICS,}

By Prof. Alfred M. Mayer, Ph.D.

(Continued from page 258).

§ VI. Capillary Attraction.

THE phenomena of capillary attraction consist in the elevation or depression of the surfaces of liquids along the line of contact with the walls of the vessels which contain them; in the ascent or depression of liquids between slightly separated plates, or in tubes of such small internal diameters as to approach to the dimensions of a hair; whence the name of capillarity, from capillus, a hair.

These effects are due to the attractions of the molecules of the

* Pelouze, Comptes Rendus, Vol. LVI., page 505; Vol. LVII., page 62.

† Schorlemwer, Chemical News, 1863, page 157. 